\title{
The effects of neem extract and azadirachtin on soil microorganisms
}

\author{
S. Sarawaneeyaruk ${ }^{1 *}$, S. Krajangsang ${ }^{1}$, O. Pringsulaka ${ }^{1}$ \\ ${ }^{1}$ Department of Biology, Faculty of Science, Srinakharinwirot University, 114 Sukhumvit 23 Wattana, Bangkok, \\ 10110, Thailand. *Corresponding author: siriruk@g.swu.ac.th
}

\begin{abstract}
Both neem extract and azadirachtin are widely used in agriculture as organic pesticides because they are nontoxic to humans, animals, and the environment. However, their effects on soil microorganisms and plant growth-promoting rhizobacteria (PGPR), which directly affect soil quality, remain largely unexplored. In this study, the effects of neem extract and azadirachtin on the activity of soil microbes and rhizosphere microorganisms was evaluated. We found that 0.1 and $0.4 \mathrm{gmL}^{-1}$ of the extract and 1.25 and $2.5 \mu \mathrm{gmL}^{-1} \mathrm{of}$ azadirachtin inhibited the activity of soil microorganisms in vitro. Treating soil with azadirachtin for two months reduced the number of microorganisms present, while two months of treatment with neem extract increased the number of microorganisms in both the soil and the rhizosphere. The phytopathogenic bacterium Pectobacterium carotovorum was more resistant to azadirachtin than Rhizobium sp. Moreover, treatment of mung beans with neem extract or azadirachtin reduced the number of root nodules and Trichoderma asperellum in the rhizosphere, when compared to the control.
\end{abstract}

Keywords: Neem extract, Azadirachtin, soil microorganisms, rhizosphere microorganisms, plant growthpromoting rhizobacteria, Rhizobium, Trichoderma

\section{Introduction}

Neem (Azadirachta indica) extract is cost-effective and environmentally friendly, and is therefore widely used as a means of controlling agricultural pests. Neem extract is composed of a complex mixture of molecules, including normal hydrocarbons, phenolic compounds, terpenoids, alkaloids, and glycosides (Hossain et al., 2013). These molecules act on various phases of an insect's life cycle, making it difficult for pests to resist the physiological effects of neem extract (Mordue-Lunt $\mathrm{Z}$ and Nisbet, 2000). Azadirachtin is the main active ingredient of neem extract, and has antifeedant and toxic effects on insects (Morgan, 2009). Azadirachtin, extracted from neem oil, is both cheap and readily available on the market. When used as an insecticide or for protecting stored seeds intended for consumption, neem extract and pure azadirachtin are both considered nontoxic to beneficial organisms such as earthworms, and safe for human 
consumption (Khalid and Shad, 2002; Boeke et al., 2004). Moreover, reports show that the use of neem extract is an effective means of controlling mosquito larvae, aphids, and whitefly (Aliero, 2003; Nzanza and Mashela, 2012). Thus, neem extract is becoming popular in organic agriculture.

Neem extract is also capable of controlling pathogenic microorganisms. In vitro, neem extract has a potential for antibacterial activity against clinical bacteria such as Pseudomonas aeruginosa, Escherichia coli, and Staphylococcus aureus, and against phytopathogenic bacteria and fungi such as Xanthomonas vesicatoria, Ralstonia solanacearum, Pythium aphanidermatum, Alternaria alternata, Bipolaris sorokiniana, Fusarium oxysporum, Helminthosporium sp., and Thielaviopsis sp. (Sukanya et al., 2009; Al-Hazmi, 2013; Jain et al., 2013). However, the effects of neem extract on soil microorganisms and plant growth-promoting rhizobacteria (PGPR) are not yet well understood.

Soil microorganisms play a crucial role in ecosystem processes, including the decomposition of organic matter and the cycling of major plant nutrients (Madigan et al., 2011). The variety of microorganisms present in a particular soil is usually an indicator of soil quality. Soil microbial biomass is a source of nutrients for plants, and is often highly correlated with the organic matter content of a soil (Pankhurst et al., 1995). PGPR, a type of bacterium inhabiting soil at and around the root surfaces (i.e., rhizosphere), promotes plant growth. Some PGPRs increase plant N or P uptake, or modulate plant hormone levels (Mohite, 2013; Etesami et al., 2014; Yadav and Verma, 2014). Other PGPRs can indirectly inhibit plant pathogens or activate induced systemic resistance (ISR) pathways (Parikh and Jha, 2012; Ahemad and Kibret, 2013). For example, the legume symbiotic bacterium Rhizobium sp. Fix esatmospheric nitrogen into ammonium suitable for use by plants. Pseudomonas sp. and Bacillus megaterium have the ability to solubilize phosphate into a form suitable for use by plants (Stajkovic et al., 2011). Trichoderma sp. is widely used as abiocontrol agent against phytopathogens, as it produces an enzyme that degrades cell walls, as well as antibiotics and secondary metabolites that inhibit the growth of phytopathogenic fungi (Vinale et al., 2008).

Land use and plant community composition can affect the composition of soil microbial communities (Waldrop et al., 2000). Okur et al., (2010) studied the effects of two organic pesticides, Drimia maritima and Euphorbia myrsinites extracts, on key processes of soil ecology. It was found that D. maritima and E. myrsinites extracts have different effects on soil microbial biomass and activity. In this study, the effects of neem extract and azadirachtin on rhizosphere and soil microorganisms were investigated from a similar perspective. The extract's possible antimicrobial activity on soil microorganisms, plant growthpromoting microorganisms, and phytopathogens were also studied. The effects of neem extract and azadirachtin on the root nodules of mung beans and the Trichoderma population in the rhizosphere were also investigated.

\section{Materials and Methods}

Neem (Azadirachta indica var. siamensis) leaves were surface-sterilized with $5 \% \mathrm{NaOCl}$ for 10 minutes, then washed five times with sterile water. The leaves were then ground and sterile water was added to achieve the desired concentration. Then, the extract was filtered through four layers of gauze and boiled for 10 minutes. To test its sterility, one milliliter of extract was used to inoculate poured plates of nutrient agar (NA) and potato dextrose agar (PDA) media. The sterile extract was storedat $4{ }^{\circ} \mathrm{C}$ until use. Azadirachtin was purchased from 
Thai Neem Products CO., LTD. (Thailand). The azadirachtin was filtered through a calcium acetate (CA) membrane filter with $0.45 \mu \mathrm{m}$ pores prior to use.

\subsection{The effects of neem leaf extract and azadirachtin on soil microorganisms}

Two types of soil are used in this study. First, commercial soil (hereafter, CS) is soil treated with chemical fertilizers frequently used in the cultivation of ornamental plants. Second, natural soil from the Bangpakong river, Chachoengsao province, Thailand (hereafter, BS) is soil not previously treated with chemical compounds. These two soil types were used in the interest of evaluating the effects of azadirachtin and neem extract on soils microorganisms in both natural and agricultural environments.

To test whether neem extract and azadirachtin inhibit soil microorganisms, serial dilutions of soil suspensions were made, and suitable dilutions were used to inoculate poured plates of NA and PDA media, which were mixed with the extract or azadirachtin to concentrations at 0.1 and $0.4 \mathrm{gmL}^{-1}$ of the neem extract or 1.25 and $2.5 \mu \mathrm{gmL}^{-1}$ of azadirachtin. These concentrations were chosen based on a report by Aliero (2003) and Ali et al. (2010), who stated that 0.1 and $0.4 \mathrm{gmL}^{-1}$ extracts could be used to control mosquito larvae and aphids, respectively. The 1.25 and $2.5 \mu \mathrm{gmL}^{-1}$ azadirachtin concentrations are those recommended by Thai Neem Products CO., LTD. for agricultural pest control. After incubation at $30{ }^{\circ} \mathrm{C}$ for 1 day, the colony-forming units (CFU) on the NA and PDA plates were counted.

To study the effects of long-term neem extract and azadirachtin application on soil microorganisms, an experiment was conducted, in which sixty pots were filled with $250 \mathrm{~mL}$ of CS soil and sixty pots were filled with $250 \mathrm{~mL}$ of BS soil. Sixty pots were divided to five groups (twelve pots each). Then, once per week for a period of two months, twelve pots of each soil type were treated with $25 \mathrm{~mL}$ of 0.1 and $0.4 \mathrm{gmL}^{-1}$ neem extract, 1.25 and $2.5 \mu \mathrm{gmL}^{-1}$ azadirachtin and the rest, used as a control, were treated with $25 \mathrm{~mL}$ of sterile water. One gram of soil obtained from 2 $\mathrm{cm}$ from the top of each pot was used to create soil suspensions. The suitable soil suspension dilutions were used to inoculate poured plates of NA and PDA. After incubation at $30{ }^{\circ} \mathrm{C}$ for 1 day, the $\mathrm{CFU}$ on the NA and PDA plates were counted.

\subsection{The effects of neem leaf extract and azadirachtin on rhizosphere microorganisms, plant growth, and mung bean root nodules}

The effects of the neem extract and azadirachtin on microorganisms in the rhizosphere were studied using mung bean as a model plant, because it is an economic plant and easy to cultivate, and any changes in the formation of root nodules by Rhizobium sp.can be easily observed. In a greenhouse, the mung beans were sown in one hundred and twenty $500-\mathrm{mL}$ pots, half of which contained CS soil and the other half contained BS soil. Sixty pots were divided to five groups (twelve pots each). Then, once a week for a period of two months, the pots were treated with 50 $\mathrm{mL}$ of either neem extract or azadirachtin, at different concentrations as described above. Pots that were used as a control were treated with sterile water. The plants were uprooted after two months. Rhizosphere soil was collected by shaking the roots gently and collecting a sample of the soil that remained stuck to the roots. The roots were then washed and blotted with a tissue to absorb the remaining water. Finally, shoot height, root length, shoot weight, and root weight were measured. The suitable rhizosphere soil dilutions were used to inoculate poured NA and PDA plates. After incubation at $30^{\circ} \mathrm{C}$ for 1 day, the number of CFU on the NA and PDA plates was counted. 


\subsection{The potential for the in vitro antimicrobial activ-} ity of neem extract and azadirachtin

Rhizobium sp. TISTR 131 and Xanthomonas campestris pv. campestris TISTR 2065 were provided by the Thailand Institute of Scientific and Technology Research. Pseudomonas sp., B. megaterium, P. carotovorum, T. asperellum, and $F$. oxysporum were provided by the microbiology laboratory, in the Department of Biology of the Faculty of Science at Srinakharinwirot University. Rhizobium sp. was cultured and tested on yeast mannitol agar (YMA) with Congo red. Other bacteria were cultured and tested on NA medium. $T$. asperellum and $F$. oxysporum were cultured and tested on PDA medium. Bacteria and fungi were identified via $16 \mathrm{~S}$ and $18 \mathrm{~S}$ rRNA gene sequencing, respectively. The antibacterial activity of the neem extract and azadirachtin was tested via the agar well diffusion method. Bacterial or fungal spore suspensions (106 cells or sporesm $\mathrm{L}^{-1}$ ) were swabbed on the medium. Then, 50 $\mu 1$ well ${ }^{-1}$ of neem extract or azadirachtin was applied. The inhibition zone was observed after incubation for 24 hours (for bacteria), or 4-5 days (for fungi).

\subsection{The effects of neem extract and azadirachtin on Trichoderma in rhizosphere}

T. asperellum spores were mixed with sterile CS soil at a final concentration of 106 spores $\mathrm{L}^{-1}$ soil. Mung bean seeds were planted in the mixed soil. After two weeks, the plants were treated with various concentrations of either the neem extract or azadirachtin for two months, as described above. After two months, the plants were uprooted and the rhizosphere soil was collected. Suitable rhizosphere soil dilutions were used to inoculate poured plates of Trichoderma-specific medium (Williams et al., 2003). The plates were then incubated at $30{ }^{\circ} \mathrm{C}$ for $10-15$ days. Finally, the number of Trichoderma colonies was counted.

\subsection{Statistical analysis}

The data were analyzed by analysis of variance (ANOVA), and the treatment means were compared using a Fisher's Least Significant Difference test (LSD) at a significance level of 0.05 .

\section{Results}

\subsection{The effects of neem extract and azadirachtin on soil microorganisms}

The effects of neem extract and azadirachtin on soil microorganisms were tested in vitro by inoculate poured NA and PDA plates with soil suspension. Both of the NA and PDA plates were mixed 1.25 or $2.5 \mu \mathrm{gmL}^{-1}$ azadirachtin or 0.1 or $0.4 \mathrm{gmL}$ ${ }^{1}$ neem extract. We found that, for both CS and BS, the plates mixed with azadirachtin at any concentration contained significantly fewer microorganisms than the control plates did (Table 1). Similar results were obtained with the neem extract. These results show that both azadirachtin and the extract exhibit antimicrobial activity that suppresses the growth of soil microorganisms. In addition, we found that two months of supplementation with 1.25 or $2.5 \mu \mathrm{gmL}^{-1}$ of azadirachtin had a significant negative impact on the microorganisms in both soils (Table 1).

However, supplementation with 0.1 or $0.4 \mathrm{gmL}^{-1}$ of neem extract for two months significantly increased the presence of microorganisms in both soils.

The results suggested that long-term application of azadirachtin exhibits antimicrobial activity. Moreover, although the neem extract exhibited antimicrobial activity against soil microorganisms in vitro, some compounds in the aqueous leaf extract might support soil microorganism growth to some extent. 
Table 1. The effects of neem extract and azadirachtin on soil microorganisms

\begin{tabular}{|c|c|c|c|c|c|c|c|}
\hline & & & \multicolumn{5}{|c|}{ Microorganisms in soil $\left(\times 10^{5} \mathrm{CFUg}^{-1}\right)$} \\
\hline & & & \multirow[t]{2}{*}{ Control } & \multicolumn{2}{|c|}{ Azadirachtin } & \multicolumn{2}{|c|}{ Neem extract } \\
\hline & & & & $1.25 \mu \mathrm{gmL}^{-1}$ & $2.5 \mu \mathrm{gmL}^{-1}$ & $0.1 \mathrm{gmL}^{-1}$ & $0.4 \mathrm{gmL}^{-1}$ \\
\hline \multirow{4}{*}{ Soil } & BS & NA & $17.52 \pm 2.68^{\mathrm{a}}$ & $0.90 \pm 0.34^{\mathrm{c}}$ & $0.60 \pm 0.25^{\mathrm{c}}$ & $4.85 \pm 1.36^{\mathrm{b}}$ & $1.97 \pm 0.29^{\mathrm{c}}$ \\
\hline & & PDA & $1.30 \pm 0.30^{\mathrm{a}}$ & $0.54 \pm 0.08^{\mathrm{bc}}$ & $0.51 \pm 0.12^{\mathrm{bc}}$ & $0.73 \pm 0.13^{\mathrm{b}}$ & $0.38 \pm 0.21^{\mathrm{c}}$ \\
\hline & CS & NA & $12.72 \pm 2.78^{\mathrm{a}}$ & $2.10 \pm 0.54^{\mathrm{cd}}$ & $0.75 \pm 0.29^{d}$ & $10.54 \pm 0.77^{b}$ & $3.58 \pm 0.65^{\mathrm{c}}$ \\
\hline & & PDA & $6.23 \pm 0.97^{\mathrm{a}}$ & $1.37 \pm 0.36^{\mathrm{d}}$ & $1.30 \pm 0.46^{\mathrm{d}}$ & $4.76 \pm 0.44^{\mathrm{b}}$ & $2.74 \pm 1.06^{\mathrm{c}}$ \\
\hline \multirow{4}{*}{$\begin{array}{l}\text { Two } \\
\text { months } \\
\text { treated soil }\end{array}$} & BS & NA & $16.59 \pm 1.66^{\mathrm{b}}$ & $7.73 \pm 1.63^{\mathrm{c}}$ & $9.43 \pm 1.44^{\mathrm{c}}$ & $27.60 \pm 4.39^{\mathrm{a}}$ & $27.01 \pm 2.01^{\mathrm{a}}$ \\
\hline & & PDA & $9.57 \pm 0.88^{\mathrm{b}}$ & $6.09 \pm 1.46^{\mathrm{c}}$ & $4.82 \pm 0.46^{\mathrm{c}}$ & $15.78 \pm 2.83^{\mathrm{a}}$ & $15.95 \pm 3.23^{\mathrm{a}}$ \\
\hline & CS & NA & $0.98 \pm 0.24^{\mathrm{b}}$ & $0.48 \pm 0.07^{\mathrm{c}}$ & $0.41 \pm 0.11^{\mathrm{c}}$ & $2.26 \pm 0.14^{\mathrm{a}}$ & $2.23 \pm 0.28^{\mathrm{a}}$ \\
\hline & & PDA & $0.52 \pm 0.16^{\mathrm{c}}$ & $0.11 \pm 0.03^{\mathrm{d}}$ & $0.12 \pm 0.02^{\mathrm{d}}$ & $2.09 \pm 0.16^{\mathrm{b}}$ & $2.66 \pm 0.34^{\mathrm{a}}$ \\
\hline
\end{tabular}

Colony forming unit (CFU) in nutrient agar (NA) or potato dextrose agar (PDA) were counted and data were shown as mean \pm standard deviation. Different superscript letters in each row indicate that there were significant differences $(p<0.05)$. ns means no significant differences. BS: Bangpakong soil; CS: Commercial soil

\subsection{The effects of neem extract and azadirachtin on rhizosphere microorganisms, plant growth, and mungbean root nodules}

After the mung beans were treated with either the neem extract or the azadirachtin for two months, the plants were uprooted and the microorganisms in the rhizosphere of each plant were quantified. We found that the number of rhizosphere microorganisms from azadirachtin-treated mung beans was not significantly different from that in the rhizospheres of the control plants grown in CS pots. However, fewer rhizosphere microorganisms were found in BS pots when the mung beans had been treated with $2.5 \mu \mathrm{gmL}^{-1}$ azadirachtin (Figure 1). As expected, rhizosphere microorganisms from the neem extract-treated mung beans outnumbered those from the rhizospheres of the control plants, regardless of the soil in which they were grown. It is likely that the rhizosphere microor- ganisms were not_affected by azadirachtin; the number of CFU from the CS pots was relatively similar to that of the control. On the other hand, soil microorganism populations were reduced significantly by the application of azadirachtin (Table 1 and Figure 1).

We also observed the growth of mung bean plants treated with either azadirachtin or neem extract.

We found that in BS pots, plants treated with 0.4 $\mathrm{gmL}^{-1}$ neem extract had root lengths, shoot lengths, and root weights similar to those of the control (Table 2). However, the mung bean shoot and root weights were heavier than those of the control when the plants were treated with $0.1 \mathrm{gmL}^{-1}$ neem extract, but lighter than the control when the plants were treated with 1.25 or $2.5 \mu \mathrm{gmL}^{-1}$ azadirachtin. Similar results were observed in plants grown in CS pots, with the shoot and root weights being lighter when plants were treated with $2.5 \mu \mathrm{gmL}^{-1}$ azadirachtin. 
Similar results were observed in plants grown in CS pots, with the shoot and root weights being lighter when plants were treated with $2.5 \mu \mathrm{gmL}^{-1}$ azadirachtin. The root weights were also lighter when the plants were treated with $0.4 \mathrm{gmL}^{-1}$ extract. These results suggest that azadirachtin negatively affects the growth of mung beans.
The number of root nodules that formed on treated mung beans was also observed. The results in Figure 2 show only the number of root nodules on mung beans in BS pots, since the number of root nodules on plants in CS pots was too few to be counted and compared to the control. These results show that mung beans treated with either azadirachtin or neem extract exhibited suppressed root nodule formation compared to the control.
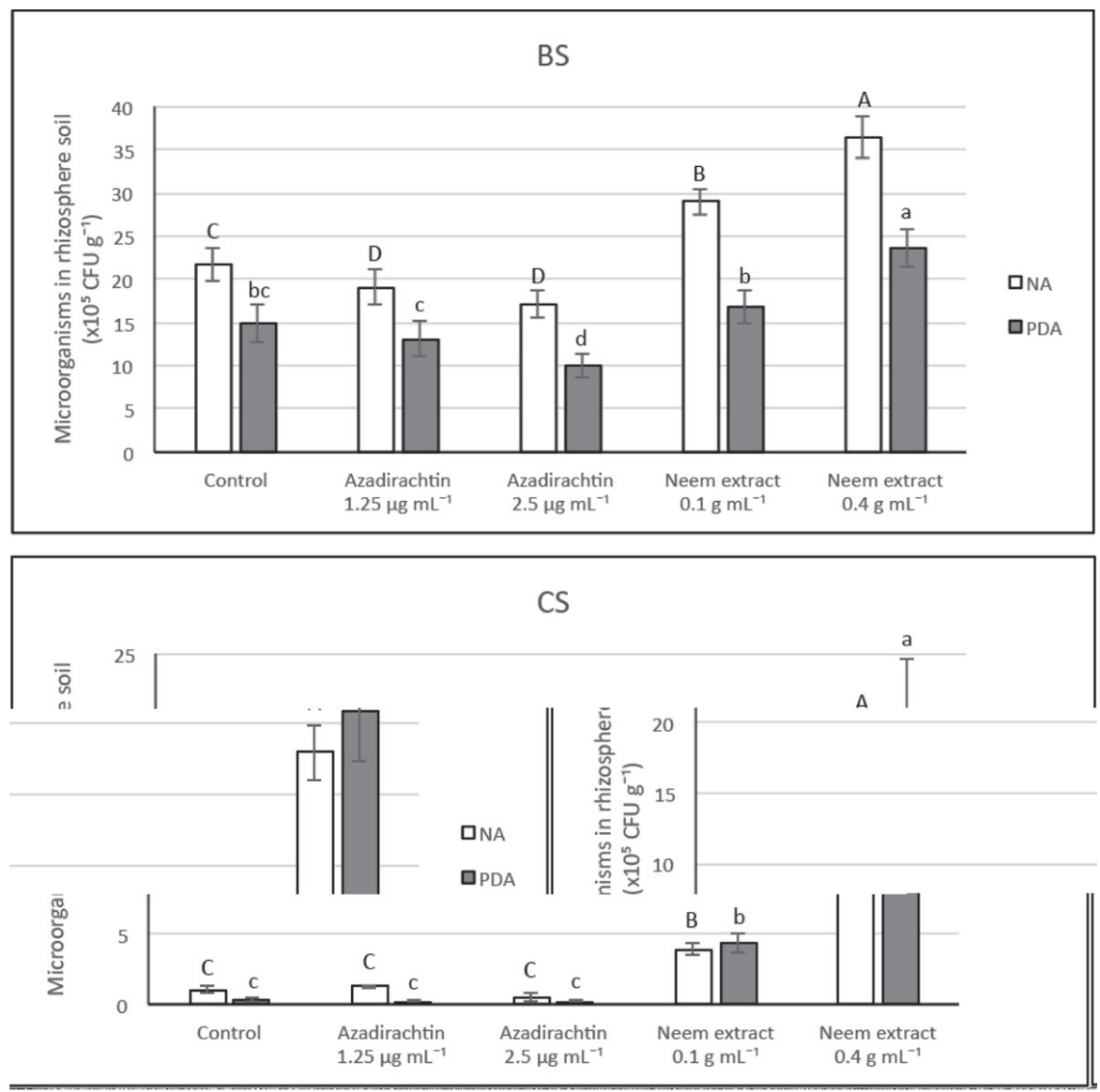

Figure 1. The effects of neem extract and azadirachtin on rhizosphere microorganisms.

Colony forming unit (CFU) in nutrient agar (NA - white bar) and potato dextrose agar (PDA - grey bar) werecounted and data were shown as mean \pm standard deviation. Different letters above bar indicate that there were significant differences $(p<0.05)$. Comparison is grouped by letter types; that is, capital lettersare for comparison among NA and lower letters for PDA. The experiments are conducted in two different soil types; BS is Bangpakong soil, and CS is Commercial soil. 
Table 2. The effects of neem extract and azadirachtin on mung bean growth.Data were shown as mean \pm standard deviation. Different superscript letters in each row indicate that there were significant differences $(p<0.05)$. ns means no significant differences

\begin{tabular}{|c|c|c|c|c|c|c|}
\hline & & Control & Azadi & achtin & Neem & xtract \\
\hline & & & $1.25 \mu \mathrm{gmL}^{-1}$ & $2.5 \mu \mathrm{gmL}^{-1}$ & $0.1 \mathrm{gmL}^{-1}$ & $0.4 \mathrm{gmL}^{-1}$ \\
\hline BS & shoot length $(\mathrm{cm})$ & $42.81 \pm 6.58^{\mathrm{ns}}$ & $39.61 \pm 5.00^{\mathrm{ns}}$ & $37.38 \pm 8.84^{\mathrm{ns}}$ & $45.33 \pm 3.20^{\text {ns }}$ & $45.67 \pm 5.72^{\mathrm{ns}}$ \\
\hline & shoot weight (g) & $3.44 \pm 1.64^{\mathrm{b}}$ & $1.80 \pm 0.86^{\mathrm{c}}$ & $1.51 \pm 0.77^{\mathrm{c}}$ & $5.58 \pm 1.51^{\mathrm{a}}$ & $3.44 \pm 1.41^{\mathrm{b}}$ \\
\hline & root length $(\mathrm{cm})$ & $19.18 \pm 4.41^{\mathrm{a}}$ & $12.61 \pm 2.63^{\mathrm{b}}$ & $14.41 \pm 4.49^{\mathrm{b}}$ & $20.45 \pm 4.03^{\mathrm{a}}$ & $19.06 \pm 3.44^{\mathrm{a}}$ \\
\hline & root weight (g) & $0.83 \pm 0.41^{\mathrm{b}}$ & $0.28 \pm 0.09^{\mathrm{c}}$ & $0.30 \pm 0.21^{\mathrm{c}}$ & $1.42 \pm 0.42^{\mathrm{a}}$ & $0.93 \pm 0.32^{\mathrm{b}}$ \\
\hline CS & shoot length $(\mathrm{cm})$ & $46.05 \pm 4.70^{\mathrm{ns}}$ & $43.50 \pm 4.51^{\mathrm{ns}}$ & $41.50 \pm 6.38^{\mathrm{ns}}$ & $44.00 \pm 8.76^{\mathrm{ns}}$ & $42.50 \pm 5.01^{\mathrm{ns}}$ \\
\hline & shoot weight (g) & $2.50 \pm 1.07^{\mathrm{a}}$ & $2.48 \pm 1.16^{\mathrm{a}}$ & $1.07 \pm 0.51^{\mathrm{b}}$ & $2.66 \pm 1.48^{\mathrm{a}}$ & $1.42 \pm 0.60^{\mathrm{ab}}$ \\
\hline & root length $(\mathrm{cm})$ & $14.15 \pm 4.52^{\mathrm{ns}}$ & $16.83 \pm 7.68^{\mathrm{ns}}$ & $13.83 \pm 6.65^{\text {ns }}$ & $16.50 \pm 3.94^{\mathrm{ns}}$ & $11.60 \pm 3.51^{\mathrm{ns}}$ \\
\hline & root weight $(\mathrm{g})$ & $1.00 \pm 0.54^{\mathrm{a}}$ & $0.48 \pm 0.09^{\mathrm{ab}}$ & $0.19 \pm 0.05^{\mathrm{b}}$ & $0.97 \pm 0.48^{\mathrm{a}}$ & $0.26 \pm 0.11^{\mathrm{b}}$ \\
\hline
\end{tabular}

Data were shown as mean \pm standard deviation. Different superscript letters in each row indicate that there were significant differences $(p<0.05)$. ns means no significant differences

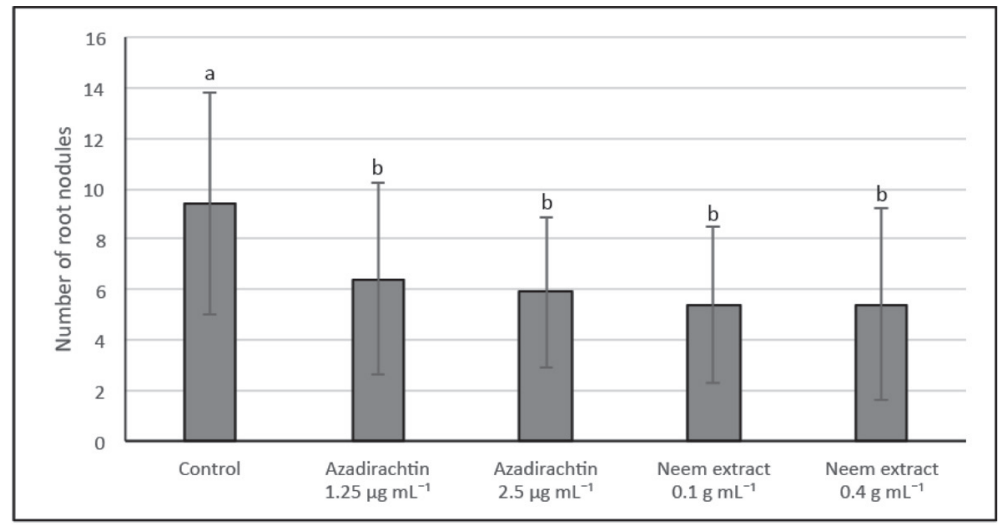

Figure 2. The effect of neem extract and azadirachtin on mung bean root nodules.

Data were shown as mean \pm standard deviation of the number of root nodules per plant. Different letters above bar indicate that there were significant differences $(p<0.05)$. 


\subsection{The potential for neem extract or azadirachtin to} exert antimicrobial effects on phytopathogens and plant growth-promoting microorganisms in vitro

We investigated thee ffects of neem extract and azadirachtin on phytopathogens and plant growth-promoting microorganisms, and attempted to identify whether they exhibit antimicrobial activity. Azadirachtin and neem extract were tested for antimicrobial activity usingagar well diffusion method. The phytopathogens tested in this study were $X$. campestris pv. campestris, $P$. carotovorum, and $F$. oxysporum, which cause black rot in crucifers, soft rot, and Fusarium wilt disease in vegetables, respectively (Agrios, 2005). Rhizobium sp. and Trichoderma sp.are well known plant growth-promoting microorganisms that are widely used in agriculture. B. megaterium and $P$. aeruginosa, have plant growth-promoting characteristics, are often found in soil (Adesemoye and Ugi, 2009; Stajkovi et al., 2011). We found that neem extract did not inhibit the growth of the microorganisms tested in this study, with the exception of B. megaterium, for which $1 \mathrm{gmL}^{-1}$ or more of neem extract could inhibit growth (Table 3). As expected, azadirachtin exhibited greater antimicrobial activity than the neem extract. Azadirachtin applied at a concentration of $0.3 \mathrm{mgmL}^{-1}$ or more could inhibit the growth of Rhizobium sp. and $X$. campestris pv. campestris. The growth of $B$. megaterium, P. aeruginosa, and $P$. carotovorum could be inhibited by azadirachtin applied at concentrations of at least $0.1,0.4$, and $0.5 \mathrm{mgmL}^{-1}$, respectively. Neither azadirachtin nor neem extract could inhibit $T$. asperellum and $F$. oxysporum Azadirachtin applied at concentrations of $0.4 \mathrm{mgmL}^{-1}$ or more resulted in late sporulation only in $T$. asperellum (data not shown).

\subsection{The effects of neem extract and azadirachtin on Trichoderma in the rhizosphere}

We investigated whether neem extract and azadirachtin can reduce the amount of Trichoderma in therhizosphere. The rhizosphere soil of treated mung beans was used to conduct plate counts on Trichoderma-specific medium. We found that neem extract and azadirachtin treatments at any concentration significantly reduced the amount of T. asperellum in the rhizosphere (Figure 3 ). However, the root length, shoot length, root weight, and shoot weight of the treated mung beans in this study were not significantly different (data not shown). These results might imply that the colonization of mung bean roots by $T$. asperellum was reduced in treated plants.

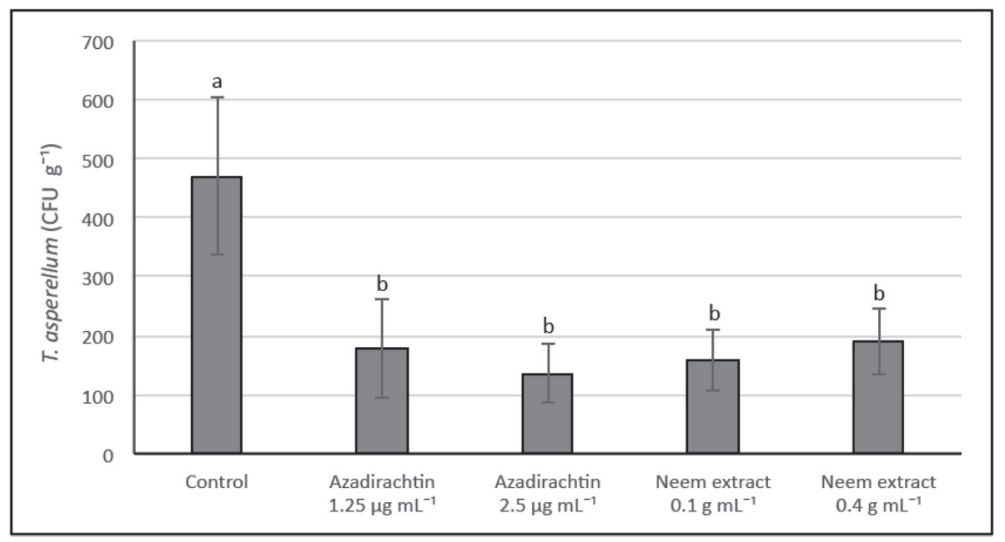

Figure 3. The effect of neem extract and azadirachtin on T. asperellum in rhizosphere.Data were shown as mean \pm standard deviation of $T$. asperellumcolonies that were found in one gram of rhizosphere soil. Different letters above bar indicate that there were significant differences $(p<0.05)$. 
Table 3. The potential for neem extract or azadirachtin to exert antimicrobial effects on phytopathogens and plant growth-promoting microorganisms in vitro

\begin{tabular}{|c|c|c|c|c|c|c|c|c|c|}
\hline & \multicolumn{9}{|c|}{ Inhibition zone (mm) } \\
\hline & \multicolumn{6}{|c|}{ Azadirachtin } & \multicolumn{3}{|c|}{ Neem Extract } \\
\hline & $\begin{array}{c}0.1 \\
\mathrm{mgmL}^{-1}\end{array}$ & $\begin{array}{c}0.2 \\
\mathrm{mgmL}^{-1}\end{array}$ & $0.3 \mathrm{mgmL}^{-1}$ & $\begin{array}{c}0.4 \\
\mathrm{mgmL}^{-1}\end{array}$ & $\begin{array}{c}0.5 \\
\mathrm{mgmL}^{-1}\end{array}$ & $\begin{array}{c}1.0 \\
\mathrm{mgmL}^{-1}\end{array}$ & $0.5 \mathrm{gmL}^{-1}$ & $\begin{array}{c}1.0 \\
\mathrm{gmL}^{-1}\end{array}$ & $\begin{array}{c}1.5 \\
\mathrm{gmL}^{-1}\end{array}$ \\
\hline B. megaterium & $1.4 \pm 0.6$ & $3.6 \pm 0.4$ & $4.5 \pm 0.5$ & $5.6 \pm 0.4$ & $6.4 \pm 0.7$ & $8.6 \pm 1.5$ & n.d. & $2.3 \pm 1.5$ & $3.7 \pm 0.8$ \\
\hline Rhizobium sp. & n.d. & n.d. & $1.4 \pm 0.6$ & $2.6 \pm 0.9$ & $3.6 \pm 0.6$ & $8.6 \pm 0.5$ & n.d. & n.d. & n.d. \\
\hline$P$. aeruginosa & n.d. & n.d. & $0.3 \pm 0.4$ & $1.7 \pm 1.2$ & $2.8 \pm 0.8$ & $5.9 \pm 0.7$ & n.d. & n.d. & n.d. \\
\hline X. campestris & & & & & & & & & \\
\hline pv. campestris & n.d. & n.d. & $2.4 \pm 1.1$ & $3.0 \pm 0.7$ & $4.0 \pm 0.7$ & $8.6 \pm 1.1$ & n.d. & n.d. & n.d. \\
\hline P. carotovora & n.d. & n.d. & n.d. & n.d. & $0.4 \pm 0.2$ & $3.6 \pm 0.5$ & n.d. & n.d. & n.d. \\
\hline T. asperellum & n.d. & n.d. & n.d. & n.d. & n.d. & n.d. & n.d. & n.d. & n.d. \\
\hline F. oxysporum & n.d. & n.d. & n.d. & n.d. & n.d. & n.d. & n.d. & n.d. & n.d. \\
\hline
\end{tabular}

Data were shown as mean \pm standard deviation. n.d. means not detected

\section{Discussion}

Our experimental results show that azadirachtin and neem extract inhibit soil microorganisms in vitro. Using GC-MS and NMR analysis, it was determined that azadirachtin is a tetranortriterpenoidin thelimonoid group (Mordue-Luntz and Nisbet, 2000; Alves et al., 2009). Although azadirachtin has been reported to be safe for the environment (Khalid and Shad, 2002; Boeke et al., 2004; Morgan, 2009), the concentrations recommended for use inagriculture -1.25 and $2.5 \mu \mathrm{gmL}^{-1}$ - are toxic tomicro organisms in the soil and rhizosphere (Table 1 and Figure 1). Neem extract is composed of antimicrobial ingredients such as alkaloids, glycosides, flavonoids, and saponins, which are common antibiotics found in plants (Pandey et al., 2014). At concentrations of 0.1 and $0.4 \mathrm{gmL}^{-1}$, neem extract inhibited the growth of soil microorganisms in vitro. However, long-term use of the extract enhanced the growth of soil and rhizosphere microorganisms (Table 1 and Figure1). This could be because some protein or carbohydrate residues in the extract are beneficial to the microorganisms. Carney and Matson (2005) reported that variations in the abundance of soil microorganisms might occur as a result of soil carbon processes. The carbon percentage of the soil was most strongly associated with changes in the composition of the microbial community. Dubey et al. (2009) found that the growth of Macrophomina phaseolina, a phytopathogenic fungus, was promoted by 
autoclaved neem extracts. They suggested that the antimicrobial ingredients present in neem extract would have been denatured by the high temperatures of the autoclave, leaving behind only nontoxic compounds or those that promote the growth of microorganisms. There have been reports of the use of neem extract for phytopathogen control. For example, neem extract could inhibit the growth of Alternaria solani (which causes early blight disease in potatoes and tomatoes), Fusarium oxysporum (which causes Fusarium wilt disease in a variety of plants), Rhizoctonia solani (which causes damping-off in a variety of seedlings), and Sclerotinia sclerotiorum (which causes Sclerotinia, or white mold disease, in most vegetables) (Moslem and El-Kholie, 2009; Hassanien et al., 2010; Al-Hazmi, 2013). In this study, the extract was also shown to inhibit the growth of soil microorganisms in vitro (Table 1). However, among the soil and phytopathogenic microorganisms tested in vitro, the extract only inhibited the growth of $B$. megaterium (Table 3). This is likely because the neem extract used in this study was water-based, and some potentially antimicrobial compounds are water-insoluble. AlHazmi (2013) found that alcohol extracts of neem seeds could efficiently inhibit phytopathogens such as Pythium aphanidermatum, Alternaria alternata, and Helminthosporium sp. However, the neem seed extract created using a water extraction process was a poor inhibitor of the same phytopathogens.

Azadirachtin inhibited a wider variety of soil and phytopathogenic bacteria than did the neem extract. This difference may be due to the small amount of azadirachtin in the neem leaf extract. It has been reported that while a small amount of azadirachtin is found in neem leaves, the compound is abundant in neem seed oil (Morgan, 2009). Alves et al. (2009) reported that azadirachtin could not be found in hydroalcoholic neem leaf extract via TLC or HPLCUV/DAD detection methods. This suggests that the antimicrobial activity of the neem extract is limited. Interestingly, the two-month long-term usage of the extract reduced the number of nodules found on the roots of mung beans, as well as the population of Trichoderma in the rhizosphere. This might be because neem extract application alters soil conditions, making them unsuitable for Rhizobium or Trichoderma colonization. Dubey et al. (2009) found that ammonia was evolved during the decomposition of neem oil and seed cakes. This ammonia production increased soil alkalinity, resulting in an increase in antimicrobial activity.

The antimicrobial activity of azadirachtin and neem extract on microorganisms in both BS and CS pots was relatively similar (Table 1 and Figure1), except during the long-term usage of azadirachtin, which did not significantly reduce the population of rhizosphere microorganisms in CS pots (Figure1). As shown in Figure 1, rhizosphere microorganisms in the BS control pots outnumbered those in the CS control pots, indicating a difference between the two microbial communities. That is, some microorganisms in the CS pots were resistant to azadirachtin, while the growth of other microorganisms in the BS pots was inhibited. The hypothetical differences in the two microbial communities, therefore, explain why rhizosphere microbes inhibited by azadirachtin were found only in the BS pots (Figure 1). In addition, plants in BS pots treated with azadirachtin developed lighter roots and shoots than the control plants (Table 2). This was correlated with the size of the microbial rhizosphere community (Figure 1), and could be because some plant growth-promoting microorganisms were inhibited by azadirachtin. This is supported by evidence from our previous study, which also showed that plant growth varies with the prevalence of rhizosphere microorganisms (Sarawaneeyaruk et al., 2014).

We found that phytopathogens such as $P$. carotovorum resisted the effects of azadirachtin more strongly than 
plant growth-promoting bacteria such as Rhizobium sp. (Table 3). Furthermore, the sporulation of $T$. asperellum was delayed by treatment with $0.4 \mathrm{mgmL}^{-1}$ or more of azadirachtin, though the same was not true for F. Oxysporum (data not shown). Additionally, T. asperellum prevalence in the rhizosphere and root nodules was significantly reduced when plants were treated with 1.25 or $2.5 \mu \mathrm{gmL}^{-1}$ azadirachtin (Figure 2 and 3 ). These results suggest that the use of azadirachtin in agriculture suppresses some plant growth-promoting bacteria, resulting in the loss of phytopathogen control or an imbalance of microbial soil ecology, eventually leading to the increased prevalence of various plant diseases. Additionally, in the BS pots, plants treated with $2.5 \mu \mathrm{gmL}^{-1}$ azadirachtin had lighter roots and shoots than the control (Table 2). Similarly, the amount of root nodules and T. asperellum in the rhizospheres of plants treated with neem extract was less than that of the control (Figure 2 and 3). This also suggests that neem extract suppresses the growth of some plant growth-promoting bacteria. However, the long-term use of neem extract enhanced the growth of microorganisms in the soil and rhizosphere (Table 1 and Figure 1). This implies that, in agricultural usage, neem extract was safer for the soil ecosystem than azadirachtin.

\section{Conclusions}

Azadirachtin and neem extract are widely used in agriculture to control insect populations. This study found that both azadirachtin and neem extract usage reduce the number of root nodules on mung bean plants, as well as the T. Asperellum population in the rhizosphere. Azadirachtin in particular reduced the populations of soil and rhizosphere microorganisms. Therefore, the use of azadirachtin and neem extract should be supplemented with organic fertilizer or the application of effective microorganisms (EM).

\section{Acknowledgements}

This work was financially supported by the faculty of Science, Srinakharinwirot University. (Grant number 196/2556)

\section{References}

Adesemoye, A.O., Ugi, E.O. 2009. Evaluating Pseudomonas aeruginosa as plant growth-promoting rhizobacteria in West Africa. Arch. Phytopathol. Plant Prot. 42, 188-200.

Agrios, G.N. 2005. Plant pathology. Elsevier academic press, Massachusetts, 358-383 p

Ahemad, M., Kibret, M. 2013. Mechanisms and applications of plant growth promoting rhizobacteria: Current perspective. J. King. Saud. Univ. 26, 1-20.

Al-Hazmi, R.H.M. 2013. Effect of neem (Azadirachta indica) leaves and seeds extract on the growth of six of the plant disease causing fungi. Glo. Adv. Res. J. Microbiol. 2, 89-98.

Ali, A., Rizvi, P.Q., Khan, F.R. 2010. Bio-efficacy of some plant leaf extracts against mustard aphid, Lipaphis erysimi kalt. on Indian mustard, Brassica juncea. J. Plant Prot. Res. 50, 130-132.

Aliero, B.L. 2003. Larvaecidal effects of aqueous extracts of Azadirachta indica (neem) on the larvae of anopheles mosquito. Afr. J. Biotechnol. 2, 325-327.

Alves, P.D., Brandão, M.G.L., Nunan, E.A.,ViannaSoares, C.D. 2009.Chromatographic evaluation and antimicrobial activity of Neem (Azadirachta indica A. Juss., Meliaceae) leaves hydroalcoholic extracts. Braz. J. Pharmacogn. 19, 510-515.

Boeke, S.J., Boersma, M.G., Alink, G.M., van-Loon, J.J.A., van-Huis, A., Dicke, M., Rietjens, I.M.C. 2004. Safety evaluation of neem (Azadirachta indica) derived pesticides. J. Ethnopharmacol. 94, 25-41. 
Carney, K.M., Matson, P.A. 2005. Plant communities, soil microorganisms, and soil carbon cycling: does altering the world belowground matter to ecosystem functioning?. Ecosystems. 8, 928-940.

Dubey, R.C., Kumar, H., Pandey, R.R. 2009. Fungi toxic effect of neem extracts on growth and sclerotial survival of Macrophomina phaseolina in vitro. J. Am. Sci. 5, 17-24.

Etesami, H., Mirseyed-Hosseini, H., Alikhani, H.A. 2014. In planta selection of plant growth promoting endophytic bacteria for rice (Oryza sativa L.). J. Soil Sci. Plant Nutr.14, 491-503.

Hassanien, N.M., Zeid, M.A.A., Youssef, K.A., Mahmoud, D.A. 2010. Control of tomato early blight and wilt using aqueous extract of neem leaves. Phytopathol. Mediterr. 49, 143-151.

Hossain, M.A., Al-Toubi, W.A.S., Weli, A.M., AlRiyami, Q.A., Al-Sabahi, J.N. 2013. Identification and characterization of chemical compounds in different crude extracts from leaves of Omani neem. J. Taibah. Univ. Sci. 7, 181-188.

Jain, D., Jayaram, L., Prabhu, M.V., Bhat, K.G. 2013. Antibacterial effect of neem (Azadirachta indica) oil on multidrug resistant bacteria isolated from human infections. Int. J. Biol. Med. Res. 4, 3544-3546.

Khalid, S., Shad, R.A. 2002. Potential advantage of recent allelochemical discoveries and agro-ecosystems. Prog. Farm. 11, 30-35.

Madigan, M.T., Martinko, J.M., Stahl, D.A., Clark, D.P. 2011. Brock biology of microorganisms. Benjamin cummings, California, 723-731 p

Mohite, B. 2013. Isolation and characterization of indole acetic acid (IAA) producing bacteria from rhizospheric soil and its effect on plant growth. J. Soil Sci. Plant Nutr. 13, 638-649.

Mordue-Luntz, A.J., Nisbet, A.J. 2000. Azadirachtin from the neem tree Azadirachta indica its action against insect. An. Soc. Entomol. Brasil. 29, 615-632.
Morgan, E.D. 2009. Azadirachtin, a scientific gold mine. Bioorg. Med. Chem. 17, 4096-4105.

Moslem, M.A., El-Kholie, E.M. 2009. Effect of neem (Azadirachta indica A. Juss) seeds and leaves extract on some plant pathogenic fungi. Pak. J. Biol. Sci. 12, 1045-1048.

Nzanza, B., Mashela, P.W. 2012. Control of whiteflies and aphids in tomato (Solanum lycopersicum L.) by fermented plant extracts of neem leaf and wild garlic. Afr. J. Biotechnol. 11, 16077-16082.

Okur, N., Tuna, A.L., Okur, B., Altunlu, H., Kayikçioglu, H.H., Civelek, H.S. 2010. Non-target effect of organic insecticides: effect of two plant extracts on soil microbial biomass and enzymatic activities in soil. Environ. Monit. Assess. 165, 389-397.

Pandey, G., Verma, K.K., Singh, M. 2014. Evaluation of phytochemical, antibacterial and free radical scavenging properties of Azadirachta indica (neem) leaves. Int. J. Pharm. Pharm. Sci. 6, 444-447.

Pankhurst, C.E., Hawke, B.G., McDonald, H.J., Buckerfield, J.C., Michellsen, P., O'Brien, K.A., Gupta, V.V.S.R. Doube, B.M. 1995. Evaluation of soil biological properties as potential bioindicators of soil health. Aus. J. Exp. Agric. 35, 1015-1028.

Parikh, K., Jha, A. 2012. Biocontrol features in an indigenous bacterial strain isolated from agricultural soil of Gujarat, India. J. Soil Sci. Plant Nutr. $12,245-252$.

Sarawaneeyaruk, S., Pringsulaka, O., Wichalek, S., Koto, R., Sukkhum, S. 2014. The effect of domestic wastewater from Thailand's Saen Saeb canal on plant growth and rhizosphere microorganisms. Songklanakarin J. Sci. Technol. 36, 627-632.

Stajkovic, O., Delic, D., Josic, D., Kuzmanovic, D., Rasulic, N., Nezevic-Vukcevic, J. 2011. Improve- 
ment of common bean growth by co-inoculation with Rhizobium and plant growth-promoting bacteria. Rom. Biotech. Lett. 16, 5919-5926.

Sukanya, S.L., Sudisha, J., Hariprasad, P., Niranjana, S.R., Prakash, H.S., Fathima, S.K. 2009. Antimicrobial activity of leaf extracts of Indian medicinal plants against clinical and phytopathogenic bacteria. Afr. J. Biotechnol. 8, 6677-6682.

Vinale, F., Sivasithamparam, K., Ghisalberti, E.L., Marra, R., Woo, S.L., and Lorito, M. 2008 Trichoderma-plant-pathogen interactions. Soil Biol. Biochem. 40, 1-10.
Waldrop, M.P., Balser, T.C., Firestone, M.K. 2000. Linking microbial community composition to function in a tropical soil. Soil Biol. Biochem. 32, 1837-1846.

Williams, J., Clarkson, J.M., Mills, P.R., Cooper, R.M. 2003. A selective medium for quantitative reisolation of Trichoderma harzianum from Agaricus bisporus. Compost. Appl. Environ. Microbiol. 69, 4190-4191.

Yadav, J.,Verma, J.P. 2014. Effect of seed inoculation with indigenous Rhizobium and plant growth promoting rhizobacteria on nutrients uptake and yields of chickpea (Cicer arietinum L.). Eur. J. Soil Sci. 63, 70-77. 